\title{
Teacher's Organizational Commitment in Mechanistic School Structures: A Study Conducted on the Job Characteristics of a Private School in Abu Dhabi
}

\author{
Hadi Fouad Masnour ${ }^{1}$ and Solomon Arulraj David ${ }^{2 *}$ \\ ${ }^{1,2 *}$ The British University in Dubai, UAE \\ ${ }^{1}$ hadifouadmansour@gmail.com, ${ }^{2 *}$ solomon.david@buid.ac.ae
}

\begin{abstract}
Organizational structures are fundamental requirements of schools; the structure determines the components of the organization, which in turn contribute to the formation of job characteristics. Job characteristics affect labor motivation and satisfaction while feeding into the organizational commitment of the staff. The study investigates the effect of mechanistic structures on job characteristics and their combined impact on job satisfaction and organizational commitment. The Job Diagnostic Survey (JDS) and Motivational Potential Score (MPS) investigate the perceptions of an international school's teaching staff in Abu Dubai, United Arab Emirates (UAE). The findings indicate teachers possess affective commitment towards the school yet perceive their roles as severely curtailed in terms of authority and autonomy and limited in their ability to utilize diverse skill sets due to the extreme specialization inherent in their roles. Teachers view the organization as highly centralized due to the bureaucracy with high degrees of specialization and formalization. Still, they are motivated due to their perception of the importance of their roles. The number of cases is the limitation of the study, although it helped to focus on depth. Future studies may consider more cases for a broader understanding.
\end{abstract}

Keywords: Organizational commitment, Job satisfaction, Job characteristics, Motivation, Mechanistic structure, Specialization, Formalization, Centralization

\section{Introduction}

Educational institutions require the interactions of people working towards a common goal and the structured organization of these people. The nature, objective, and size of the institution may help dictate the 'appropriate' structure. The decided structure will influence the division of roles, creation of specializations, decision-making authority, degrees of delegation and interaction, and the processes within the institution [33].

Schools are traditionally bureaucratic with structures reinforced by formalization that impacts operations and place a great deal of value and authority in the top leadership roles, historically the principal. This structure has been viewed as the formalization of rules and procedures [81] focusing mainly on differentiated positions and distribution of authority to allow the increased predictability and control of performance as determinants of organizational effectiveness. Ouchi [74] posited that complexity, centralization,

Article history:

Received (March 31, 2021), Review Result (May 1, 2021), Accepted (June 5, 2021) 
formalization, and professional latitude directly influence the effectiveness of management. Centralization of authority has limited the ability of teachers to participate in the operational practices of the school. Overspecialization further reinforces the centralization of authority; teachers are grouped as subject-based departments with limited horizontal interaction between departments.

This structural rigidity enabled the traditional bureaucratic nature of schools [62]. It gave rise to the concerns of Hoy and Sweetland [46] that view forced consensus, high degrees of organizational control, and one-way communication as the antithesis of 'enabling organizations' with lasting ramifications on teaching and learning practices as well teacher's commitment.

Organizational commitment is defined as "the relative strength of an individual's identification with, and involvement in a particular organization" [68] focuses on the individual's commitment to the organization and not the job via characteristics such as an emotional attachment, a fear of loss and a sense of obligation [53]. Organizational commitment is the degree of association the employee has towards the organization [23]; increased association of goals implies a higher degree of commitment.

Policymakers, senior and middle leadership, and teachers are directly affected by the organizational structures, further impacting the level of education students receive. The chosen structure will determine the formal interactions of organizational members and their relations to one another. Commitment is an essential factor in determining and forecasting behaviors within an organization [32][54]; these behaviours are linked to job performance, creating a beneficial interest in the study of commitment to the organization. This study will investigate the organizational structure, degrees of mechanistic bureaucratization, and levels of commitment of a specific international school utilizing the mixed methods approach via a case study to achieve an in-depth understanding of a process on an individual or group [24].

Two theoretical frameworks will be utilized; (1) Mintzberg's Framework [65] will explain the organizational structure, while (2) the Organizational Commitment Theory [67] will provide the dimensions necessary to view teacher's commitment. Given the implications of a commitment labor force to the organization's objectives and the effect leadership has on its employees' general attitude and performance, this study seeks to understand the role organizational structures play in predicting the future success and failures of the school. Studies have shown that organizational commitment is a better predictor of outcomes than organizational structures, yet this study will attempt to establish a direct link between the two. The study aims to investigate the association between organizational structures and job characteristics to commitment and motivation.

\section{Literature review}

All organizations have a skeletal framework as the foundation of all functions and affect member behaviors [81]. The structure aims to minimize the differences in individual members and determine the distribution of power and authority [38] to influence the efficacy of and commitment to the organization [95]. Educational institutions are organized to determine the lines of communication and authority between individuals affecting the nature and characteristics of the roles (autonomy, affiliation, and achievements), thereby affecting perceived commitment and motivation.

Research on bureaucratic structures resulted in positive and negative relations with organizational citizenship and teachers' academic optimism [13][14]. Further research identified a negative relationship between bureaucracy and teacher capacity for collaboration, 
self-efficacy, and commitment [46]. Bureaucratic (mechanistic) schools developed certain elements such as the formalization of the structure [61][62] and assigning importance to the focused direction of command (centralization) [44].

The organizational structure is the official arrangements between members of an organization in terms of tasks and duties [33], providing the organization a form to function [71]. The structure is a series of components referred to as the 'Structural Dimensions; earlier studies bifurcated the dimensions of an organizational structure based on their characteristics. 'Structural' characteristics describe its physical characteristics (levels of hierarchy, span of control, chain of command) while 'Structuring' detail and control the actions carried out (specialization/complexity, formalization, centralization).

Table 1. Structuring dimensions

\begin{tabular}{|c|c|}
\hline Structural & Structuring \\
\hline Levels of hierarchy (Size) & Specialization/Functional (Complexity) \\
\hline Span of Control & Formalization/Standardization \\
\hline Chain of Command & Centralization \\
\hline
\end{tabular}

Pugh et al. termed the structural dimensions as 'configuration,' the overall size and shape of the organizational structure; Porter and Lawler [77] showed a significant relationship to job satisfaction. It is worth mentioning that higher levels within the organization showed greater satisfaction [30][76][83]; the position within the hierarchy had a more significant influence on satisfaction (attitude) than demographic variables [31]. The span of control dictated job complexity and was related to satisfaction [41], when coupled with the member's disposition, it can significantly affect job satisfaction [18][35][47][94]. This study focuses on structuring, the functioning of an organization via specialization, formalization, and centralization. Hatch [40] claimed that specialization, formalization, and centralization are related to job satisfaction: the first two are the best predictors of the structure's nature. The last is negatively related to job satisfaction [85].

The organizational structure encompasses two forms; physical and social; this study focused its attention on Social Theoretical Structures. Theoretical structures are distinguishable as organic and mechanistic [93] structures. Organic systems utilize a less rigid design that encourages task complexity, minimizes formalization, and decentralizes authority [93]. Increased specialization and high degrees of formalization (coercive) indicate a mechanistic structure that utilizes centralization (hindering) to determine the distribution of authority. Mechanistic systems are centralized with downward vertical communication, while organic forms encourage creativity, innovation, and collaboration with decisions reached through consensus.

Specialization has been defined as the varied functional tasks undertaken within the organization [75][80], while complexity is the sum of specializations [37]. A great deal of ambiguity has arisen from specialization and complexity; the former denotes the rationality of an organizational structure while the latter focuses on the actual practice of roles funneled into narrower functions. The study understands specialization as functional complexity, the tasks performed by the teacher, and their degree of variety.

Formalization (standardization) refers to formally prescribed, appropriate, and codified activities within the organization, while standardization operates to restrict behavior to a set of procedures that manage expectations. Formalization can be separated into (1) coercive and (2) enabling [46]; standardization gives rise to the coercive nature of bureaucracy as it requires member compliance over autonomy, at times by force of punishment [1]. Such 
coercive school structures limited teacher responsibility and innovation due to increased control placed on them and expected to abide by strict formalizations [43]. Enabling formalization maintains rules, regulations, and procedures while empowering members to identify and implement solutions to their problems. Formalization, by its nature, is aimed at controlling behavior, punishing those that do not follow behavioural prescriptions [46]. This bureaucratic structure has been criticized [68] due to its inability to promote creativity, minimize professional and personal growth, reduce input in decision-making, reward conformity, ignore the informal substructures, and simplify communication lines. Formalization can limit the scope and create a monotonous routine that leads to dissatisfied employees and higher levels of voluntary turnover and recorded absences [45][47]. It should be noted that a minimal level of formalization in education is necessary to minimize role ambiguities [82].

Centralization determines the 'locus of authority, decision-making, and members' participation in the process; decentralization implies greater participation [46]. Centralization can be divided into (1) hindering and (2) enabling. The former emphasizes the importance of discipline to minimize uncertainty [46], complementing coercive formalization as it reduces the ability to problem-solve independently [45]. Enabling centralization completes enabling formalization in that it provides a greater degree of member autonomy and decision-making authority. With high levels of centralization, mechanistic structures tended to have adverse effects on the member's perceptions [20]. They performed poorly compared to organic structures as the latter's implementation led to improved employee job satisfaction. This poor performance is especially true for those who desire accomplishment, autonomy, and authority [63] limited due to formalization and centralization. Authority or involvement in decisionmaking can alter member perceptions of an organization [88], which affects commitment [96]

Job satisfaction is the most studied subject relating to organizational members' attitudes [52]; Spector defined Job Satisfaction in terms of people's feelings fostered towards the job as whole and specific areas of it. It reflects the perceived joy the member derives from exerting effort at work [86]; this is a subjective process based on individual members and different situations. Job satisfaction encompasses three components based on evaluation, mental cognition, and behaviours; the evaluative component is linked to accomplishment and association, the cognitive to perceptions of the job's importance and complexity while the behavioural element relates to the organizational members' actions [16]. Two distinct types of satisfaction emerge, one relating to the general feeling towards work (Global) and the second to specific areas of the job (Facet Satisfaction) such as formalization, centralization, and specialization [70]. Job satisfaction is measured subjectively by the individual; the type of work and the organizational characteristics are the significant influencers of satisfaction [49]. Hackman and Oldham [72] hypothesized that if the organization could integrate specific attributes into the job, it would increase motivation and satisfaction. Previous studies support the proposition that job characteristics affect job satisfaction, and a positive correlation exists amongst teachers [78]. Hackman and Oldham [72] listed the components of job characteristics as task variety (skill complexity), task identity, task significance, autonomy, and feedback. The above elements are explained in greater detail via previous studies on the topic and have been shown to have a high relation to professional commitment [10].

The number of skills and talents required determines the level of task variety [21]. Increased standardization in mechanistic structures reduces the job's complexity by lowering the skill variety needed, reducing its ability to fulfill an employee. The power and responsibility of an employee to complete the job from start to finish encompasses task identity [60]; the more significant the task identity, the more likely the employee will be 
responsible for completing the work in its entirety to reach the objective [36]. The perceived relative importance of the job and its overall impact on the employee, co-workers, and external stakeholders [60] defines task significance. The more critical the job is to its overall success, the more significant it is to the employee and the more satisfaction derived from it. Autonomy is the employee's ability to freely determine the steps to performing the job freely. Increased autonomy increases the feeling of self-responsibility [79] and job satisfaction as the job is more interesting [60]. This autonomy extends to centralization and involvement in decision making (autonomy of decisions); more involvement improves job satisfaction [56] as they feel of greater significance to the organization. Feedback has been determined as imperative to satisfaction [59] and an intrinsic motivator [87]. It continuously provides the employee with information on their performance and their effectiveness in the organization. Jobs able to incorporate feedback and autonomy enjoyed higher job satisfaction [42] because the employee would improve themselves and their work based on the feedback [50].

Table 2. Components of job satisfaction

\begin{tabular}{|c|c|}
\hline Meaningfulness of work & $\begin{array}{r}\text { The effort exerted on behalf of the organization is of some value or meaning to } \\
\text { the employee (Skill variety, Task Identity, Task Significance) }\end{array}$ \\
\hline Responsibility & $\begin{array}{c}\text { Ability to exercise a degree of freedom and autonomy in the job and tasks } \\
\text { performed }\end{array}$ \\
\hline Knowledge of outcomes & $\begin{array}{r}\text { The provision of feedback from multiple sources to the employee to provide a } \\
\text { sense of awareness of requirements and expectations }\end{array}$ \\
\hline
\end{tabular}

Perceived satisfaction from the job is an effective response to the job characteristics [86]. A strong relationship between job satisfaction and commitment has been established in service industries [97], placing satisfaction as a commitment component. Martin and Bennett [67] advocated job satisfaction's ability to forecast organizational commitment; the individual joins the organization to provide their skills and abilities in return to satisfy their needs [84]

Organizational commitment is the employee's relationship to the organization and their desire to continue employment at the organization, as commitment is a psychological state. Three approaches to understanding organizational commitment exist [64]; this study has focused on two termed the affective and continual commitments reflecting the employee's acceptance of the organizational mission and fear of loss, respectively.

Affective commitment, the employee's acceptance of the organizational goals and mission and implies an active choice to remain due to an identification with the organization. Mowday [69] detailed four sources of affective commitment: (1) the individuals' characteristics, (2) the organizations' characteristics, (3) the nature of the work, and (4) experience derived by the individual from work. Continual commitment is based on the employee's perceived loss (sidebet) from leaving the organization, including qualitative costs such as wasted time and energy [10]. Additionally, employees will calculate the loss in benefits, familiarity with the work and work relationships they may have developed; continual commitment may also stem from a lack of alternative options in employment.

Specific demographic considerations affect commitment with varying results. Gender has been considered, with some researchers finding female teachers as slightly more committed to the organization [58] while others identified no differences [19][67]. The number of years in the organization also reflected negative findings with research pointing to increased commitment over time [8] [92] and specifically for teachers [51][22] while others found the complete opposite to be true [3]. Due to the expanse of demographics, this study has focused 
on the personal needs dimension of the individual's characteristics and their achievement as predictors of organizational commitment and job satisfaction.

Individuals join organizations with existing wants and needs in the hopes that they will be satisfied [85]. This study isolated four such needs: (1) accomplishment, (2) association, (3) autonomy, (4) and authority; the strength of these needs at specific points in time can measure motivation [81]. The satisfaction of these personal needs is an essential determinant of commitment [89] and job satisfaction [53]. Studies have found a positive relationship between commitment and accomplishment and association, but harmful compared with autonomy and no ties with authority; Steers [90] isolated the accomplishment dimension as the most influential of the four. Morris and Snyder [66] added autonomy to accomplishment, claiming they both act as forecasters of commitment and satisfaction, further related to accomplishment and authority [30].

\section{Methodology}

A brief contextual background of the scope of the study would be supportive in designing the empirical study. The study was carried out in an international private school located in Abu Dhabi (AD), the UAE. There are not many closely related similar studies in the UAE, while some of the cross-cutting local studies are worth mentioning. David [27] observes that the educational sector has been growing steadily in the UAE. The country has addressed both expansion and excellence strategically [28]. UAE has as well emerged as an educational hub for learning mobility [26]. El Afife et al [31] explored the leadership styles that influence students' learning environment in Abu Dhabi, UAE and indicate a positive organizational environment supporting organizational justice. Al Husseini et al. [6] identified that school leaders demonstrate instructional leadership abilities by supervising, observing classes, offering feedback, reviewing lesson plans, helping in curriculum and assessments, and encouraging teachers' professional growth. Daraghmeh et al. [25] researched observed a strong tendency of school leaders in the UAE to use technology tools as a substitution to the conventional ones with null or minimal functional improvement. Bashaireh et al. [12] highlighted the ways appreciative leadership affects teachers' well-being positively. Albash et al. [4] pointed out that school leaders play important role in supporting teachers in engaging teaching and learning practices. Al Samkari et al. [7] suggest that authentic leadership support staff engagement. David \& Abukari [29] recommend leadership practices to pay careful attention to local culture and context. Al Hassanieh et al. [5] accounted for the effect of distributed leadership on school governance. Baroudi et al. [11] indicate the role of mentorship in leadership development.

A descriptive approach was employed; quantitative data was collected via a cross-sectional survey to gather quantitative information from the teaching staff using a random stratified sampling method with a target population of 135 staff members in an international school in Abu Dhabi. Based on Krejce and Morgan's [55] sample size model, the sample size determined for this study was 135 to include all staff members; 86 surveys were returned from the 135 distributed. Slight modifications to the language were suggested and implemented before conducting the full-scale survey. A professional translation of the questions a trial run were conducted on Arabic and Islamic studies to ensure all staff members can complete the survey; no changes were suggested. A paper-based survey was distributed to the staff in person during a school-wide meeting; many respondents completed and submitted their opinions immediately. 
Interviews were conducted with the Heads of the Department to gather in-depth reasoning. The interviews are limited to the Heads of the Department due to their exposure to the entire teaching staff, their subordinates' opinions, and a more intimate understanding of the power structure and decision-making process. Interviews were conducted with the educational Heads of the Department regarding their insight into the organizational structure and its rationale and an interpretation of teachers' perceptions regarding teachers' authority, achievement, autonomy, skill variety, and the nature of their commitment. Structured interviews maximized the interviews' reliability; the questions underwent a pilot run with coordinators to ensure the language is clear.

The independent variable was the mechanistic bureaucratic school structure viewed in terms of specialization, centralization, and formalization; the dependent variable was the job satisfaction- organizational commitment concept, including job characteristics and personal needs. The researcher provided the necessary information regarding the purpose as well as data collection, analysis, and interpretation methods. Respondents may exercise the option of not responding to any question they feel is uncomfortable as a means of ensuring privacy [15].

Formalization, centralization, and specialization were measured using a survey to establish a baseline of perceptions regarding mechanistic bureaucracy. Affective and continuance commitment was measured using a four-question survey; each item was measured using a 1 (inaccurate) to 4 (accurate) Likert-type scale. Personal Needs were measured using a modified version of the Manifest Needs Questionnaire (MNQ) developed by Steers and Braunsteir [91]. MNQ was selected due to its continued use in research to measure manifest needs [9][16][48]. Participants respond on a four-point Likert scale ranging from "strongly agree" to "strongly disagree." A modified Job Diagnostic Survey (JDS) measured job characteristics, originally used to measure four scales (variety, autonomy, feedback, and friendship on the job) with five items each [36]. The modified JDS used a four-point rating scale to measure four core dimensions: skill variety, task significance, feedback, and autonomy.

The tools used in this study have been utilized and scrutinized in-depth by experts in previous research to the point where this study can comfortably claim content validity and provided the predictability required to demonstrate reliability [34].

\section{Results and discussion}

The research was conducted on the entire 135-teaching staff of an international K-12 private school in Abu Dhabi, UAE, with a participation rate of $64 \%$. Interviews conducted with the Heads of (subject) Departments provided additional support to the assertions made by the survey. Surveys aided in triangulating the data and provide a deeper insight into the results. Perceptions of the structure regarding specialization, formalization, and centralization overwhelmingly strongly agreed that the school is mechanistic seen in the high mean of all three structuring components [Table 1]. The mechanistic perception was more concentrated on centralization and formalization, supporting the belief that they are a natural consequence of the industry and need to be regulated. Specialization presented the only criteria whereby some strongly disagreed with the bureaucratic nature of their roles due to the small minority of teachers that occupy secondary positions within the school, including coordination and pastoral roles. This supported research on the increased perception of task variety and satisfaction with members higher in the chain of command. 
Teacher's Organizational Commitment in Mechanistic School Structures: A Study Conducted on The Job Characteristics of a Private School in Abu Dhabi

Table 3. Structuring and commitment

\begin{tabular}{|c|c|c|c|c|c|c|}
\hline & $\begin{array}{c}\text { Strongly } \\
\text { Disagree }\end{array}$ & Disagree & Agree & $\begin{array}{c}\text { Strongly } \\
\text { Agree }\end{array}$ & Mean & $\begin{array}{c}\text { Standard } \\
\text { Deviation }\end{array}$ \\
\hline Formalization & $0.0 \%$ & $3.5 \%$ & $36.0 \%$ & $60.5 \%$ & 3.57 & 3.08 \\
\hline Centralization & $0.0 \%$ & $17.4 \%$ & $39.5 \%$ & $43.0 \%$ & 3.26 & 2.81 \\
\hline Specialization & $3.5 \%$ & $12.8 \%$ & $44.2 \%$ & $39.5 \%$ & 3.20 & 2.77 \\
\hline $\begin{array}{c}\text { Affective } \\
\text { Commitment }\end{array}$ & $4.7 \%$ & $18.6 \%$ & $58.1 \%$ & $18.6 \%$ & 2.91 & 2.47 \\
\hline $\begin{array}{c}\text { Continuance } \\
\text { Commitment }\end{array}$ & $17.4 \%$ & $31.4 \%$ & $39.5 \%$ & $11.6 \%$ & 2.45 & 2.10 \\
\hline
\end{tabular}

Teachers under 35 years old perceive the existence of centralization more acutely than those above 35 years old, attributed to a generational difference in terms of their perceptions of power structures. As the number of years of experience increases, teachers are more inclined to agree with the degree of centralization. Furthermore, female teachers are less likely to perceive centralization, possibly due to the differences in gender perceptions of authority. Female teachers more readily accept and work within the power structures that exist, while male teachers may seek greater authority or reject the control of others over them. Specialization was a point of contention, with female staff least likely to agree with overspecialization and most inclined to feel a sense of skill variety in their roles. Newer staff members disagree with older staff members regarding the degree of role specialization; as time increases and the novelty of the new position is diminished, staff become accustomed to the repetitive nature of their roles, altering the perception of specialization.

The fact that specialization is the only structuring criteria that presented a sample of respondents that strongly disagree reflects the degree of control that teachers have over their specific roles, which is greater than making organization-based decisions and setting formal rules and procedures. Teachers with the least levels of experience in the school ubiquitously agree, to a varying degree, of the existence of rigid rules and procedures. Those with more experience (> 4years) have a small population that disagrees with the notion of formalization. As school experience, teachers begin gauging rules and regulations more accurately, which may be circumvented for efficiency, thus reducing the perception of formalization.

Affective commitment reflects the degree of acceptance of the objectives and shared values; 58\% of the staff agreed with the overall mission and goals of the school, a concept readily accepted in the research considering the nature of teaching and its mission to educate and be responsible for the youth. Every demographic agreed with the organization's goals reflected in the relatively high mean [Table 1]. A small percentage of those who strongly disagree implies a sincere lack of affective organizational commitment; these members would most likely remain due to the continuance commitment or possibly be the most likely candidates for turnover and high absenteeism. This generates a concern if the staff members are committed to the organization's goals or illustrating a more professional commitment to their role as teachers.

Although many are affectively committed, 52\% remain due to limited choices; continuance commitment is the perceived lack of choice (side-bet theory) that seeks to minimize the loss due to departure. Continuance commitment is least prevalent among newer staff and female teachers. The school has a predominantly female staff body that is married and under the sponsorship of their spouses; this would provide an alternative to their roles, minimizing their fears of leaving the organization and the assumptions of the side-bet theory. New entrants 
may feel less continually committed ad they have less perceived investment in the organization.

The Job Diagnostic Survey conducted illustrated teachers' views on specific components of their roles regarding skill variety (linked to specialization), task significance, feedback, and autonomy (linked to centralization). The highest score each job characteristic can achieve is a 4 , while the overall motivational potential score is a 64. Centralization and specialization curtailed teachers' ability to act independently and utilize a broader range of skills; however, department heads emphasized the importance of feedback as a form of control and motivation.

Autonomy achieved the lowest score, which falls in line with the previous assessment of centralization. Due to the high perception of centralization and formalization, many would feel a lack of autonomy and power over specific roles. Those with lesser experience in the school score their autonomy slightly higher due to their limited exposure to the school and its standard operations. The minor differences are negligible and may be averaged out shortly into the future once the new teacher is accustomed to centralizing and formalizing their roles. The feedback scored highest in the overall perception of the job; it is evident that teachers feel they receive adequate feedback from supervisors and outside stakeholders regarding their job performance. New teachers also scored feedback higher than their more experienced counterparts, a common fact as new teachers are more subject to appraisals to ensure they have acclimated. Parents and students are more likely to voice opinions (feedback) regarding new teachers that they have had limited exposure to in the past. Older teachers $(>35$ years old) have scored above the school average regarding how they view job characteristics. Skill variety may be perceived differently by more senior teachers. They may apply different teaching methods, giving the impression of being multi-skilled or more likely since older teachers are offered more expansive teaching roles than newer teachers.

It is worth noting that newer teachers perceive their roles as more significant to the organization; this does not imply a lack of significance of the older teachers but simply a more acute assessment of their relevance to the organization developed over time and exposure. Furthermore, it seems that increased experience in the field humbles the opinions of autonomy in a mechanistic structure, leads to less feedback as the nature and efficacy of their work become more knowledgeable and their views on the importance and significance of their task to the organization overall. Teachers perceive autonomy and authority as limited in the organization due to its structure yet are satisfied via feedback received and rolesignificance as educators.

The modified MNQ ranked authority lowest as a motivator given the nature of education in terms of its centralization and formalization, limiting the possibility of delegation; however female teachers seek this attribute more than males. Yet, it remains a potential motivator and may be achieved through more minor concessions of authority and control regarding the specific job roles. Achievements' ability to motivate is limited, especially when considering the inherent specialization of the job; without room to expand the position, the ability to gain new levels of achievement is limited, and whatever is currently achieved may seem boring when repeated over time. As the level of experience increases, the motivating potential of achievement decreases; the less experienced teacher's scoring may be related to the novelty of their roles. Not having the breadth of experience may still leave room for motivation by carrying out what more experienced teachers may consider repetitive. Affiliation may be easier to achieve; association to different groups through cross-curriculum initiatives and small group-centered responsibilities may provide new scope for affiliation. 
Interestingly, males are most motivated by affiliation, while female teachers rank achievement as the highest. Authority becomes more motivational with older teachers desiring more as they evolve in the organization and gain more experience- they want to apply and direct their roles. More experienced and older staff members seek authority over affiliation; this is understandable when taken when they have already been inducted into and experienced the different possible social groupings. The opposite is true for newly indicted staff. Their exposure to the multiple social structures that exist is limited; they are more eager to satisfy their social needs than seek esteem and self-actualization goals.

Female teachers scored lower than male teachers in motivation; this may be understood when considering what they perceive as motivational- authority and achievement are limited when we believe the mechanistic structure of schools. Consistently, newer teachers $(<10$ years in the industry $\&<4$ years in the school) scored higher in motivation. This indicates that motivation within the sector falls over time, and commitment begins to shift from affective to continuance. Overall, many of the different demographics have ranked specific job characteristics as crucial, including autonomy and authority; however, they remain limited due to the existing organizational structure and its inherent centralization-overt specialization limited teacher ability to progress and achieve and feel more valuable to the overall organization.

\section{Conclusion}

This thesis aimed to investigate the effects of organizational structure in terms of three components (centralization, specialization, formalization) and their impact on specific job characteristics, influencing motivation/satisfaction and organizational commitment. A survey was conducted on the entire staff of an international school located in the United Arab Emirates (Abu Dhabi), which resulted in a high participation rate. This school demonstrated the characteristics of a hierarchical, bureaucratic mechanistic structure. Staff perceptions of structure tend towards a centralized and formalized structure due to the nature of the industry responsible for the care of minors. Staff roles in teaching are highly specialized, with greater focus placed on subject-based skills that limit the ability of teachers to use a broader range of skills; those with more significant experience in education are more inclined to agree with the bureaucratic nature of the school. Analyzing job characteristics determined staff members' perception of skill variety, task significance, feedback, and autonomy. The respondents polled similarly in stating that their current roles lacked autonomy and skill variety, the inability to make decisions within the organization, and limited use of a 'wide' range of skills linked to the organizational structure. Teachers perceive their roles as significant due to their function as educators or their middle management roles. Feedback from the power structure as well as from their roles within the school

The researched commitment (affective and continuance) illustrated teachers' desire to stay within the organization, and the sample displayed more significant affective commitment over the continuance. More teachers accept the organization's objectives as the imputes for commitment; the number may be diluted due to professional commitment. However, the sample did present a considerable perception of continuance commitment among the sample. Achievement, affiliation, and authority constitute the motivational factors researched; the aim is to determine what factors may lead to greater job satisfaction and organizational commitment. Authority was ranked lowest due to an acceptance of the mechanistic structure within educational institutions. Achievement and affiliation rank highest in motivational 
potential but with varying degrees based on demographics, while feedback may have aided in creating a sense of accomplishment.

The overwhelming majority agree regarding the mechanistic nature of the school, yet specialization is a point of contention in that some do not believe their roles are overly specialized. Due to the standardization of rules and procedures and the formalization of the organization, this case study presents a coercive bureaucracy coupled with a hindering centralization of authority and decision making. Educational institutions perceived specialization and centralization as hindering and coercing teachers' behavior however the need for formalization is inherent in the sector. This social structure may benefit from a more organic social structure that encourages collaboration and creativity.

\section{References}

[1] K. A. Abu Afifeh and S. A. David, "Identifying leadership styles that influence students' learning environment: Perspectives from five schools in Abu Dhabi," UAE, Research Demagogue, vol.3, no.1, pp.4045, (2016)

[2] P. Adler and B. Borys, "Two types of bureaucracy: Enabling and coercive,” Administrative Science Quarterly, vol.41, no.1, pp.61-89

[3] G. Ahmady, M. Mehrpour, and A. Nikooravesh, "Organizational Structure," Procedia - Social and Behavioural Sciences, vol.230, pp.455-462, (2016)

[4] W. Albasha and S. A. David, "Teacher's perspectives on engaged teaching: Study from an American curriculum school in Dubai, Specialty Journal of Knowledge Management, vol.4, no.2, pp.1-13, (2019)

[5] R. Al Hassanieh and S. A. David, "The influence of distributed leadership on effective school governance and improved school performance: A study conducted in two private schools in the UAE," vol.7, no.1, (2020)

[6] A. Al Husseini and David, "The impact of head teachers' instructional leadership role on teachers' professional practices in four private schools in Dubai," the UAE, Research Nebula, vol.6, no.1, pp.23-28, (2017)

[7] H. Al Samkari and S. A. David, "The role and impacts of authentic leadership on staff engagement and performance: A study among school leaders and teachers in private schools in the UAE," Specialty Journal of Psychology and Management, vol.5, no.4, pp.65-78, (2019)

[8] H. Angle, J. Perry, "Organisational commitment: Individual and organizational influences," Work and Occupations, vol.10, no.2, pp.123-146

[9] O. Arogundade, A. Arogundade, and O. Oyebanji, "Influence of perceived organizational justice on teachers' commitment in selected secondary schools in Lagos State, Nigeria," Journal of Scientific Research and Reports, vol.4, no.7, pp.605-613, (2015)

[10] S. Aryee, Y. Chay, and J. Chew, "An investigation of the predictors and outcomes of career commitment in three career stages," Journal of Vocational Behaviour, vol.44, pp.1-16

[11] S. Baroudi and S. A. David, "Nurturing female leadership skills through peer mentoring role: A study among undergraduate students in the United Arab Emirates," Higher Education Quarterly, vol.74, no.4, pp.458-474, (2020), https://doi.org/10.1111/hequ.12249

[12] S. Bashaireh and S. A. David, "Appreciate leadership and teacher's subjective well-being: An appreciative tool for an appreciative outcome," Specialty Journal of Psychology and Management, vol.5, no.3, pp.46-63, (2019)

[13] K. Beard, "An exploratory study of academic optimism and flow of elementary school teachers," Electronic Thesis or Dissertation, (2008), Retrieved from https://etd.ohiolink.edu

[14] K. Beard, W. Hoy, and A. Woolfolk Hoy, "Academic optimism of individual teachers: Confirming a new construct,” Teaching and Teacher Education, vol.26, no.5, pp.1136-1144, (2010) 
[15] E. Bell and A. Bryman, "The ethics of management research: An exploratory content analysis," British Journal of Management, vol.18, no.1, pp.63-77, (2011)

[16] D. A. Bernstein and P. W. Nash, "Essentials of psychology (4th ed.)," Boston, MA: Houghton Mifflin Company, (2008)

[17] J. W. Berry, "Immigration, acculturation and adaptation,” Applied Psychology, vol.46, pp.5-68

[18] M. Blood and C. Hulin, "Alienation, environmental characteristics, and worker responses," Journal of Applied Psychology, vol.51, no.3, pp.284-290

[19] N. Bruning and R. Snyder, "Sex and position as predictors of organizational commitment," Academy of Management Journal, vol.26, no.3, pp.485-491

[20] T. Bucic and S. Gudergan, "The impact of organizational settings on creativity and learning in alliances," $I$, vol.7, no.3, pp.257-273, (2004)

[21] M. Buys, C. Olckers, and P. Schaap, 'The construct validity of the revised job diagnostic survey," South African Journal of Business Management, vol,38, no.2, pp.33-40, (2007)

[22] Y. Cheng, "The relationships of job attitudes and organizational commitment to different aspects of organizational environment," ERIC Document Reproduction Service No. ED 318779

[23] A. Cohen, "Multiple commitments in the workplace: An integrative approach," Mahwah, NJ: Lawrence Erlbaum Associates, (2003)

[24] J. Creswell, "Research design: Qualitative, quantitative and mixed methods approach," (2nd ed.), Thousand Oaks, CA: SAGE Publications, (2003)

[25] H. A. R. Daraghmeh and S. A. David, "Benchmarking of educational leaders' technology utilization: A study of the attitudes of education leaders in using technology in the UAE," Education Research Journal, vol.7, no.3, pp.48-58, (2017)

[26] S. A. David et.al, "An exploration into student learning mobility in higher education among the Arabian gulf cooperation council countries," International Journal of Educational Development, vol.55, pp.41-48, (2017)

[27] S. A. David, "Internationalization of higher education in the UAE and the implications for undergraduate student's institutional choice for postgraduate studies," Transitions: Journal of Transient Migration, vol.1, no.2, pp.235-250, (2017)

[28] S. A. David, "Knowledge convergence towards economic polarization: Undergraduate students' postgraduate course choice in the UAE," International Journal of Knowledge Management Studies, vol.8, no.3-4, pp.316328, (2017)

[29] S. A. David and A. Abukari, "Perspectives of teachers on the selection and the development of the school leaders in the United Arab Emirates," International Journal of Educational Management, (2019), DOI: 10.1108/IJEM-02-2019-0057

[30] G. Dreher, "Individual needs as correlates of satisfaction,” Journal of Vocational Behaviour, vol.17, no.1, pp.89-94

[31] S. El Alfy and S. A. David, "Investigating organizational justice in higher education in U.A.E," International Journal of Management in Education, vol.11, no.2, pp.163-187, (2017)

[32] D. Farrell and C. Rusbult, "Exchange variables as predictors of job satisfaction, job commitment, and turnover: The impact of rewards, costs, alternatives, and investments," Organisational Behaviour and Human Performance, vol.27-28, pp.78-95

[33] B. Fidler, "School leadership: Some key ideas," School Leadership and Management, vol.17, no.1, pp.23-38

[34] M. Grosof and H. Sardy, "A research primer for the social and behavioral sciences," Journal of Marketing Research, vol.24, no.1, pp.131

[35] J. Hackman and E. Lawler, "Employee reaction to job characteristics, Journal of Applied Psychology Monograph, vol.55, no.3, pp.259-286

[36] J. Hackman and G. Oldham, "Development of the job diagnostic survey," Journal of Applied Psychology, vol.60, no.21, pp.159-170 
[37] J. Hage and R. Dewar, "Elite values versus organizational structure in predicting innovation," Administrative Science Quarterly, vol.18, no.3, pp.279-289

[38] E. Hall, "Nonverbal communication for educators," Theory into Practice, vol.26, no.1, pp.364-367

[39] J. D. Handyside, "Satisfactions and aspirations," Occupational Psychology, vol.35, no.4, pp.213-244

[40] M. J. Hatch, "Organization theory: Modern, symbolic, and postmodern perspectives," Oxford: Oxford University Press

[41] J. Herman and C. Hulin, "Studying organizational attitudes from individual and organizational frames of reference," Organizational Behavior and Human Performance, vol.8, no.1, pp.84-108

[42] G. Hirst, P. Budhwar, B. Cooper, M. West, C. Long, X. Chongyuan, and H. Shipton, "Cross-cultural variations in climate for autonomy, stress and organizational productivity relationships: A comparison of Chinese and UK manufacturing organizations," Journal of International Business Studies, vol.39, no.8, pp.1343-1358, (2008)

[43] J. Hoy, "Legal professions: Work, structure, and organization," Contemporary Sociology, vol.32, no.6, pp.761, (2003)

[44] W. K. Hoy, "An analysis of enabling and mindful school structures. Some theoretical, research and practical considerations," Journal of Educational Administration, vol.41, no.1, pp.87-108, (2003)

[45] W. Hoy and C. Miskel, "Educational administration: Theory, research, and practice," NASSP Bulletin, vol.62, no.422, pp.115-116

[46] W. K. Hoy and S. R. Sweetland, "Designing better schools: The meaning and nature of enabling school structure," Educational Administration Quarterly, vol.37, no.3, pp.296-321, (2001)

[47] C. Hulin and M. Blood, "Job enlargement, individual differences, and worker responses," Psychological Bulletin, vol.69, no.1, pp.41-55

[48] S. Ivarsson and B. Ekehammar, "Women's entry into management: Comparing women managers and nonmanagers," Journal of Managerial Psychology, vol.16, no.4, pp.301-314, (2001)

[49] S. M. Jex, "Organizational psychology: A scientist-practitioner approach," New York, NY: John Wiley \& Sons, Inc., (2002)

[50] J. Johari, K. Yahya, D. Mit, and A. Omar, "The dimensions of job characteristics: A validation study in a Malaysian context," International Business Management, vol.5, no.2, pp.91-103, (2011)

[51] P. Jorde-Bloom, "Closing the gap: An analysis of teacher and administrator perceptions of organizational climate in the early childhood setting," Teaching and Teacher Education, vol.4, no.2, pp.111-120

[52] T. A. Judge, J. E. Bono, and E. A. Locke, "Personality and job satisfaction: The mediating role of job characteristics, Journal of Applied Psychology, vol.85, no.2, pp.237-249, (2000)

[53] R. M. Kanter, "Commitment and social organization: A study of commitment mechanisms in Utopian communities,” American Sociological Review, vol.33, no.4, pp.499-517

[54] J. Koch and R. Steers, "Job attachment, satisfaction, and turnover among public sector employees, Journal of Vocational Behavior, no.12, no.1, pp.119-128

[55] R. Krejcie and D. Morgan, 'Determining sample size for research activities," Educational and Psychological Measurement, vol.30, no.3, pp.607-610

[56] L. Lim and F. Ling, "Human resource practices of contractors that lead to job satisfaction of professional staff," Engineering, Construction and Architectural Management, vol.19, no.1, pp.101-118, (2012)

[57] C. Martin and N. Bennett, "The role of justice judgments in explaining the relationship between job satisfaction and organizational commitment," Group \& Organization Management, vol.21, no.1, pp.84-104

[58] J. Mathieu and D. Zajac, "A review and meta-analysis of the antecedents, correlates, and consequences of organizational commitment," Psychological Bulletin, vol.108, no.2, pp.171-194, (1990)

[59] A. A. Matubber and K. M. Miah, "A comparative study of job satisfaction of the Islamic bank and the conventional bank employees in Bangladesh," Journal of Behavioural Sciences, vol.12, pp.19-32, (2001)

[60] M. McShane, S. Nirenburg, and B. Jarrell, "Modeling decision-making biases," Biologically Inspired Cognitive Architectures, vol.3, pp.39-50, (2013) 
[61] L. McGuigan and W. Hoy, "Principal leadership: Creating a culture of academic optimism to improve achievement for all students," Leadership and Policy in Schools, vol.5, no.3, pp.203-229, (2006)

[62] R. McGuigan, "Integral conflict analysis: A comprehensive quadrant analysis of an organizational conflict," Conflict Resolution Quarterly, vol.22, no.3, pp.349-363, (2005)

[63] I. Meadows, “Organic structure, satisfaction, and personality,” Human Relations, vol.33, no.6, pp.383-392

[64] P. J. Meyer and J. N. Allen, "Commitment in the workplace: Theory, research, and application," Thousand Oaks, CA: Sage

[65] H. Mintzberg, "Structure in fives: Designing effective organizations," Upper Saddle River, NJ: Prentice Hall

[66] J. H. Morris and R. A. Snyder, "A second look at the need for achievement and need for autonomy as moderators of role perception-outcome relationships," Journal of Applied Psychology, vol.64, no.2, pp.173178

[67] C. Mottaz, "Determinants of organizational commitment," Human Relations, vol.41, no.6, pp.467-482

[68] R. T. Mowday, L. M. Porter, and R. M. Steers, "Employee-organisational linkage," New York: Academic Press

[69] R. T. Mowday, R. M. Steers, and 1. W. Porter, "The measurement of organizational commitment," Journal of Applied Psychological Association, vol.74, pp.152-156

[70] C. W. Mueller and S. -W. Kim, “The contented female worker: Still a paradox?” Hegtvedt, K.A. and ClayWarner, J. (Ed.) Justice (Advances in Group Processes, Vol. 25), Emerald Group Publishing Limited, Bingley, pp.117-149, (2008), DOI: 10.1016/S0882-6145(08)25006-X

[71] D. Nelson and J. Quick, "The theory of preventive stress management: A 33-year review and evaluation," Stress and Health, vol.27, no.3, pp.182-193, (2011)

[72] G. Oldham and J. Hackman, "Relationships between organizational structure and employee reactions: Comparing alternative frameworks," Administrative Science Quarterly, vol.26, no.1, pp.66-83

[73] C. A. O'Reilly and D. F. Caldwell, "Informational influence as a determinant of perceived task characteristics and job satisfaction,” Journal of Applied Psychology, vol.64, no.2, pp.157-165

[74] W. Ouchi, "The relationship between organizational structure and organizational control," Administrative Science Quarterly, vol.22, no.1, pp.95

[75] R. Payne and R. Mansfield, "Correlates of individual perceptions of organizational climate," Journal of Occupational Psychology, vol.51, no.3, pp.209-218

[76] L. W. Porter, "Job attitudes in management: Perceived deficiencies in need fulfillment as a function of job level,” Journal of Applied Psychology, vol.46. no.6, pp.375-384, DOI: 10.1037/h0047808

[77] L. Porter and E. Lawler, "Properties of organization structure in relation to job attitudes and job behavior, Psychological Bulletin, vol.64, no.1, pp.23-51

[78] L. Porter and R. Steers, "Organizational commitment, job satisfaction, and turnover among psychiatric technicians," Journal of Applied Psychology, vol.59, no.5, pp.603-609

[79] J. Price and C. Mueller, "On the causal ordering of job satisfaction and organizational commitment," Academy of Management Journal, vol.29, no.4, pp.847-858

[80] D. Pugh, D. Hickson, C. Hinings, and C. Turner, "Dimensions of organization structure," Administrative Science Quarterly, vol.13, no.1, pp.65-105

[81] S. Ranson, B. Hinings, and R. Greenwood, "The structuring of organizational structures," Administrative Science Quarterly, vol.25, no.1, pp.1-17

[82] J. Rizzo, R. House, and S. Lirtzman, "Role conflict and ambiguity in complex organizations," Administrative Science Quarterly, vol.15, no.2, pp.150-163

[83] B. Rosen, "Family structure and achievement motivation," American Sociological Review, vol.26, no.4, pp.574-585

[84] D. Roy, R. Kahn, D. Wolfe, R. Quinn, J. Snoek, and R. Rosenthal, "Organizational stress: Studies in role conflict and ambiguity,” American Sociological Review, vol.30, no.4, pp.620 
[85] H. Sims, A. Szilagyi, and R. Keller, "The measurement of job characteristics," Academy of Management Journal, vol.19, no.2, pp.195-212

[86] P. E. Spector, "Job satisfaction: Application, assessment, causes and consequences," California, Thousand Oaks: Sage Publications

[87] G. Spreitzer, M. Kizilos, and S. Nason, "A dimensional analysis of the relationship between psychological empowerment and effectiveness satisfaction, and strain," Journal of Management, vol.23, no.5, pp.679-704

[88] R. Steers, "Problems in the measurement of organizational effectiveness," Administrative Science Quarterly, vol.20, vo.4, pp.546-558

[89] R. Steers, "Antecedents and outcomes of organizational commitment," Administrative Science Quarterly, vol.22, no.1, pp.46-56

[90] R. Steers, "Individual differences in participative decision-making," Human Relations, vol.30, no.9, pp.837847

[91] R. Steers, and D. Braunstein, "A behaviorally-based measure of manifest needs in work settings," Journal of Vocational Behavior, vol.9, no.2, pp.251-266

[92] J. Stevens, J. Beyer, and H. Trice, "Assessing personal, role, and organizational predictors of managerial commitment," Academy of Management Journal, vol.21, no.3, pp.380-396

[93] T. Burns and G. Stalker, "The Management of innovation," Tavistock, London, England

[94] A. Turner and P. Lawrence, "Industrial jobs and the worker: An investigation of response to task attributes," American Sociological Review, vol.30, no.5, pp.810

[95] A. Van de Ven, “A framework for organization assessment," Academy of Management Review, vol.1, no.1, pp.64-78

[96] H. Welsch and H. LaVan, "Inter-relationships between organizational commitment and job characteristics, job satisfaction, professional behavior, and organizational climate," Human Relations, vol.34, no.12, pp.10791089

[97] S. Yung Chou and E. Lopez-Rodriguez, "An empirical examination of service-oriented organizational citizenship behavior,” Managing Service Quality: An International Journal, vol.23, no.6, pp.474-494, (2013) 
Teacher's Organizational Commitment in Mechanistic School Structures: A Study Conducted on The Job Characteristics of a Private School in Abu Dhabi

This page is empty by intentions. 